\title{
Refillable Bi-Electrolyte Fuel Cell and New Range-Extending Charging-Driving Mechanism for Electric Vehicles
}

\author{
Mu-Jung Kao and Chen-Yang $\mathrm{Wu}^{1^{*}}$ \\ Department of Vehicle Engineering, National Taipei University of Technology, Taipei 10608, Taiwan \\ ${ }^{1}$ Graduate Institute of Mechanical and Electrical Engineering, National Taipei University of Technology, \\ Taipei 10608, Taiwan
}

(Received August 31, 2015; accepted March 1, 2016)

Keywords: aggregation, precipitation, range-extending, wheel motor, anion exchange membrane

Currently, people are attempting to replace vehicles powered by fossil fuels with electric vehicles in an effort to reduce energy problems and air pollution. However, up to now this attempt has not been successful owing to safety deficiencies, short cruising ranges, and inconvenience. In this study, we have developed a safe, convenient, and refillable bi-electrolyte fuel cell to serve as a generator for electric vehicles and to supply auxiliary power to the vehicles. In terms of power, we have designed a new range-extending, charging-driving mechanism, which is a simple mechanical device that can also increase the cruising range, torque, and speed of electric vehicles and can charge while driving. After mixing 3-9 $\mu \mathrm{m}$ of zinc powder with $40 \mathrm{wt} \% \mathrm{KOH}$ electrolyte and setting the open circuit voltage to $1.4 \mathrm{~V}$, we use a constant voltage method to test with a current density of $70 \mathrm{~mA} / \mathrm{cm}^{2}$, a power density of $0.53 \mathrm{~W}$, a constant voltage of $0.3 \mathrm{~V}$, and a reaction area of $25 \mathrm{~cm}^{2}$.

\section{Introduction}

Owing to increasing problems of environmental pollution caused by conventional gasolinepowered vehicles, electric vehicles are receiving more and more attention. An electric vehicle uses a battery as the source of its power and is driven by an electric motor, thus being independent of fossil fuel and environmentally friendly. In general, when considering the power supply of electric vehicles, we take into account the following viewpoints: (1) We know that vehicle batteries have to be charged. When the electricity in a battery is used up, the electric vehicle stops running and must be recharged. Time spent waiting and searching for charging stations, which are not as numerous as gas stations, causes consumers to give up the idea of buying electric vehicles. Therefore, finding a way to extend the time of battery use and improve the torsion and speed performance are goals that industries should work toward. (2) We use fuel cells to supply electricity to electric vehicles. The term fuel cell generally refers to a device in which the chemical energy of hydrogen or a hydrogen-rich fuel (e.g., natural gas and methanol) is directly transformed into electrical energy through electrochemical reactions. Nevertheless, the waiting time to charge existing rechargeable batteries is very long, and a dense network of charging stations has not yet been established. As for hydrogen-oxygen fuel cells, they also require hydrogen fueling stations. The storage,

${ }^{\bar{*}}$ Corresponding author: e-mail: calvintp@ms61.hinet.net 
transportation, and filling of hydrogen, which has hazards associated with its supply and cannot be easily controlled, must be managed safely. Nowadays, the proton exchange membrane fuel cell (PEMFC) has been widely used around the world. However, the current hydrogen storage technology still presents barrier to widespread use. For example, when hydrogen is stored as a compressed gas, which has great possibilities for fire and explosion, the energy density per unit that hydrogen can provide is quite low. In addition, high energy-loss rate of hydrogen under a highpressure storing condition is another concern. On the other hand, even though the energy density increases by storing hydrogen in the liquid state after cooling it below $-253{ }^{\circ} \mathrm{C}$, the process of liquefaction is expensive. Still, according to recent research, it is impossible to store hydrogen in the solid state because of the great instability of solid hydrogen that has been established by scientists at the Lawrence Livermore National Laboratory.(1) To use exchangeable fuel cells, one must rely on time- and labor-consuming exchange stations, which causes further inconvenience for their use. Therefore, exchangeable fuel cells are not as convenient as refillable fuel cells (e.g., a bi-electrolyte fuel cell that contains both solid and liquid electrolytes). ${ }^{(2)}$ Since the fuel in a bielectrolyte fuel cell is in solid form, users can easily purchase a fuel cell at different places, such as convenient stores, supermarkets, and gas stations. This provides users a convenient way to replace a spent fuel cell.

In this study of bi-electrolyte fuel cells, after the zinc powder anode is directly mixed with the $\mathrm{KOH}$ electrolyte, problems of aggregation and precipitation always arise, blocking the channels and disabling the battery. In our previous study, we solved these two problems by using chemical microcell methods. ${ }^{(3)}$ In this study, we have developed a simpler and easier way to solve these problems. We mix untreated zinc powder with the electrolyte and then use press-milling to break the aggregated zinc clusters into smaller grains, thereby eliminating the aggregation problem. However, the precipitation issue was still not resolved by this treatment. We redesigned a new fuel cell that contains new anode channels to solve the precipitation problem, and also incorporated a new cathode channel to prevent the cathode from using a large amount of polytetrafluoroethylene (PTEE) to stop electrolyte leakage, which would cause a consequent problem of insufficient air input volume. Regarding the application of the solid electrolyte, we abandoned our original attempt to use asbestos because of environmental concerns. Instead, we use a new anion exchange membrane to avoid using nonwoven fabric-made separators, which cause anode cross over and result in extremely dangerous battery short circuits.

The reaction in a refillable bi-electrolyte fuel cell is shown as follows: ${ }^{(3)}$

$$
\begin{gathered}
\mathrm{Zn}+2 \mathrm{OH}^{-} \rightarrow \mathrm{Zn}(\mathrm{OH})_{2}+2 \mathrm{e}^{-} \\
\mathrm{Zn}(\mathrm{OH})_{2}+2 \mathrm{OH}^{-} \rightarrow \mathrm{Zn}(\mathrm{OH})_{4}{ }^{2-} \\
\mathrm{Zn}(\mathrm{OH})_{4}{ }^{2-} \rightarrow \mathrm{ZnO}+\mathrm{H}_{2} \mathrm{O}+2 \mathrm{OH}^{-} \\
\text {Anode } \mathrm{Zn}+2 \mathrm{OH}^{-} \rightarrow \mathrm{ZnO}+\mathrm{H}_{2} \mathrm{O}+2 \mathrm{e}^{-} \quad E^{0}=1.25 \mathrm{~V}
\end{gathered}
$$

The existence of zincate species containing $\mathrm{Zn}^{2+}$, such as $\mathrm{ZnO}, \mathrm{Zn}(\mathrm{OH})_{2}, \mathrm{ZnO}_{2}{ }^{2-}$, and $\mathrm{Zn}(\mathrm{OH})_{4}{ }^{2-}$, depends on thermodynamic conditions $\left(\mathrm{OH}^{-}\right.$concentration and temperature $)$and is also affected by kinetics, such as supersaturation with zincate. ${ }^{(4)}$

Oxygen can be reduced to hydroxyl ions according to the following reaction:(5) 


$$
\text { Cathode: } 1 / 2 \mathrm{O}_{2}+\mathrm{H}_{2} \mathrm{O}+2 \mathrm{e}^{-} \rightarrow 2 \mathrm{OH}^{-} \quad E^{0}=0.40 \mathrm{~V}
$$

However, the direct electrochemical (four-electron) reduction to hydroxide ions described in Eq. (5) is generally slow and occurs only in the presence of special catalysts. In the absence of such a catalyst (e.g., on the surface of a carbon substrate), the electrochemical (two-electron) reduction to peroxide ions is dominant as the cathodic reaction in a zinc-air battery:(4)

$$
\mathrm{O}_{2}+\mathrm{H}_{2} \mathrm{O}+2 \mathrm{e}^{-} \rightarrow \mathrm{O}_{2} \mathrm{H}^{-}+\mathrm{OH}^{-}
$$

Thus, the peroxide ions formed are generally unstable and decompose via the disproportionation reaction of oxygen to produce hydroxide ions and molecular oxygen:(4)

$$
\begin{gathered}
\mathrm{O}_{2} \mathrm{H}^{-} \rightarrow \mathrm{OH}^{-}+1 / 2 \mathrm{O}_{2} \\
\text { Overall: } \mathrm{Zn}+\frac{1}{2} \mathrm{O}_{2} \rightarrow \mathrm{ZnO} \quad E^{0}=1.65 \mathrm{~V}
\end{gathered}
$$

Teorell proposed in 1935 that there were fixed ions being charged on ion exchange membranes. In the surrounding solution, the membrane would attract counter ions of opposite charge which would pass through the membrane by osmosis. The membrane, having fixed ions of negative charge, attracted cations, and was called a cation membrane; the membrane that attracted anions was called an anion membrane. ${ }^{(6,7)}$ Cole and Tanaka named the same process of the counter ion concept. ${ }^{(8,9)}$ Water management and water movement in an alkaline anion exchange membrane (AAEM) are shown in Table 1.(10-12)

There are some disadvantages of using cation exchange membranes in direct methanol fuel cells (DMFCs): (1) The performance measured the power output per unit area of the methanol fuel cell is $1 / 10$ to $1 / 5$ that of the hydrogen fuel cell, so the methanol fuel cell performance is poor. (2) When the fuel cell works, the intermediate class CO generated during anodizing can easily cause catalyst poisoning, significantly reducing the rate of oxidation of methanol. To counter this, a large amount of precious metal platinum must be used, so the cost prohibitively high. (3) Usually resistance performance of the proton exchange membrane's fuel is poor, hence, fuel migrates from the anode to the cathode through the ion exchange membrane, resulting in methanol penetration and fuel cell short circuit, thus greatly reducing both the open circuit voltage of the DMFC and the efficiency of the cell. ${ }^{(13)}$ As to the advantages of using an AAEM: (1) Under alkaline conditions, the oxidation rate of fuel is faster and the fuel cell is more efficient. (2) Electrode catalyst poisoning is avoided. Instead, general metal electrodes are used, such as silver or nickel, greatly reducing the costs. (3) For the methanol alkaline fuel cell, the moving direction of hydroxyl ions is opposite to that of methanol permeation, reducing the permeated amount of methanol and avoiding a short circuit of the battery.

In 1839, W. R. Grove published his first research report on fuel cell, proposing the use of a single cell with hydrogen as fuel and oxygen as oxidant. ${ }^{(6,14)}$ In 1962, DuPont successfully developed perfluorinated sulfonic acid (PFSA) membrane. ${ }^{(15)}$ In 1966, DuPont for the first time applied the membrane to a hydrogen fuel cell and found that the cell's performance was dramatically improved. ${ }^{(15)}$ In 1972 a dedicated polymer electrolyte membrane, Nafion, was successfully developed for the DuPont fuel cell. ${ }^{(14)}$ In the same year, DuPont launched a series of polymer membranes, under the name Nafion, of different thicknesses for use in PEMFCs. A study of PEMFC was jointly carried 
Table 1

Water management and water movement in an AAEM. ${ }^{(10-12)}$

\begin{tabular}{|c|c|c|c|c|}
\hline & Anode & AAEM & Cathode & \\
\hline $\mathrm{OH}^{-}$is consumed at the anode. & & $\leftarrow$ & & $\mathrm{OH}^{-}$is generated at the cathode. \\
\hline & & $\leftarrow$ & & $\begin{array}{l}\mathrm{OH}^{-} \text {is produced in the cathode catalytic } \\
\text { layer. }\end{array}$ \\
\hline Water is generated at the anode. & & $\rightarrow$ & & Water is consumed at the cathode. \\
\hline $\begin{array}{l}\text { Water is produced from electrochemical } \\
\text { reaction at the anode catalytic layer. }\end{array}$ & & $\rightarrow$ & & \\
\hline $\begin{array}{l}\text { If the anode holds more water, water } \\
\text { may back-diffuse from the anode to the } \\
\text { cathode. }\end{array}$ & & $\rightarrow$ & & $\begin{array}{l}\text { If the anode holds more water, water } \\
\text { may back-diffuse from the anode to the } \\
\text { cathode. }\end{array}$ \\
\hline $\begin{array}{l}\text { Owing to water concentration and } \\
\text { pressure differences between the anode } \\
\text { and cathode, water may move between } \\
\text { the anode and cathode. }\end{array}$ & & $\leftrightarrow$ & & $\begin{array}{l}\text { Owing to water concentration and } \\
\text { pressure differences between the anode } \\
\text { and cathode, water may move between } \\
\text { the anode and cathode. }\end{array}$ \\
\hline $\begin{array}{l}\text { Water may diffuse between the anode } \\
\text { and the cathode when a concentration } \\
\text { difference exists, because the AAEM is } \\
\text { thin. }\end{array}$ & & $\leftrightarrow$ & & $\begin{array}{l}\text { Water may diffuse between the anode } \\
\text { and the cathode when a concentration } \\
\text { difference exists, because the AAEM is } \\
\text { thin. }\end{array}$ \\
\hline $\begin{array}{l}\text { In the alkaline electrolyte, water } \\
\text { molecules can usually combine with } \\
\mathrm{OH}^{-} \text {. Therefore, water can be dragged } \\
\text { from the cathode catalytic layer to the } \\
\text { anode catalytic layer by moving } \mathrm{OH}^{-} \\
\text {through the AEM, i.e., } \\
\text { water electro-osmotic drag effect. }\end{array}$ & & $\leftarrow$ & & $\begin{array}{l}\text { In the alkaline electrolyte, water } \\
\text { molecules can usually combine with } \\
\mathrm{OH}^{-} \text {. Therefore, water can be dragged } \\
\text { from the cathode catalytic layer to the } \\
\text { anode catalytic layer by moving } \mathrm{OH}^{-} \\
\text {through the AEM, i.e., } \\
\text { water electro-osmotic drag effect. }\end{array}$ \\
\hline $\begin{array}{l}\text { Water can be supplied by the externally } \\
\text { humidified hydrogen. }\end{array}$ & $\rightarrow$ & & $\leftarrow$ & $\begin{array}{l}\text { Water can be supplied by the externally } \\
\text { humidified air/oxygen. }\end{array}$ \\
\hline $\begin{array}{l}\text { Water can be supplied by the externally } \\
\text { humidified hydrogen. Water is generated } \\
\text { at the anode, and water electro-osmotic } \\
\text { drag effect and anode water flooding } \\
\text { occur. }\end{array}$ & & & & $\begin{array}{l}\text { Water can be supplied by the externally } \\
\text { humidified air/oxygen. Water can be } \\
\text { supplied by the anode; otherwise, the } \\
\text { cathode becomes dehydrated. }\end{array}$ \\
\hline
\end{tabular}

out in the United States and Canada using $50-150 \mu \mathrm{m}$ highly conductive Nafion and Dow PFSA membranes to increase fuel cell performance several fold. Then, Pt/C catalyst replaced the pure Pt black, and the catalytic layer was added with the PFSA resin by using membrane electrode assembly (MEA) technology. Finally, the output power density of the fuel cell was up to $0.5-2 \mathrm{~W} /$ $\mathrm{cm}^{2}$; the specific power of weight was $700 \mathrm{~W} / \mathrm{kg}$; and the specific power of volume was $1000 \mathrm{~W} / \mathrm{L} .{ }^{(16)}$ Because of the use of Nafion cation exchange membrane, PEMFC would hopefully develop rapidly. It is hoped that in the future a perfect anion exchange membrane will be developed for use in fuel cells that will promote fuel cell performance.

Indirectly driven electric vehicles, in which a motor is substituted for the engine, generate power through a speed slowdown mechanism of the gears, causing the vehicles to have low cruising endurance and poor efficiency. A direct drive motor has been suggested to be mounted on the axle, making the motor power haul the electric car directly, without the need to slow down the speed and the transmission system. The overall driving system of the vehicle is more efficient, and the vehicle weight is reduced, naturally upgrading vehicle performance. 
In this study, we not only solve the above problems of the fuel cell, but also improve the performance of electric vehicles by inventing a new direct-driving device for electric vehicles. It is a range-extending charging device especially suitable for electric vehicles. ${ }^{(17)}$ It makes use of a clever configuration of the wheel motor and planetary gear assembly to increase the cruising range, torque, and speed of an electric vehicle, charges while driving, and provides the auxiliary power fuel cell with the required oxygen.

\section{Materials and Methods}

\subsection{Materials}

A bi-electrolyte fuel cell mechanism is shown in Figs. 1-3. It uses zinc powder as the anode fuel and alkaline electrolyte as the liquid electrolyte. The cathode uses the oxygen in air as the oxidizer and uses the solid electrolyte of the anion exchange membrane instead of the nonwoven cloth-made separator, since the separator would make the anode cross over to the cathode and cause an extremely dangerous battery short circuit. In this study, we applied the bi-electrolyte fuel cell mechanism, a metallic material made from a nickel plate with higher conductivity and strength than a graphite plate.

Despite the drawback of being heavy, a metallic plate is extremely easy to smelt and form. There is no need for dies or molds, mass production of the metallic plate can be carried out, and the total weight can be decreased without compromising strength. When a cell stack of numerous graphite plates connected together is pressurized and locked, it may easily crack and break, and therefore, the number of plates that can be stacked is limited.

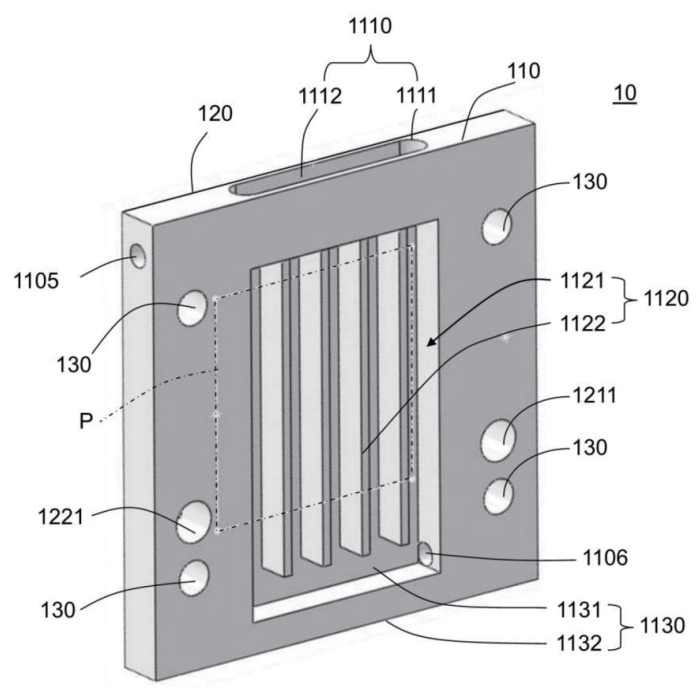

110 Anode mechanism

1105 Circulating electrolyte inlet

1120 Anode channel unit

1122 Anode conductive plate

Fig. 1. 3D drawing of anode mechanism on the front side of the bipolar plate of a bi-electrolyte fuel cell mechanism.

1106 Circulating electrolyte outlet

1121 Anode channel

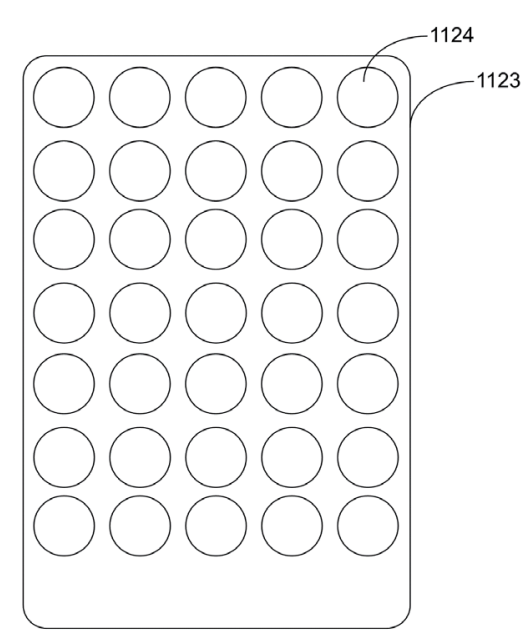

1123 Anode conductive sheet 1124 Anode conductive sheet flow hole

Fig. 2. Schematic diagram of an anode conductive sheet. 


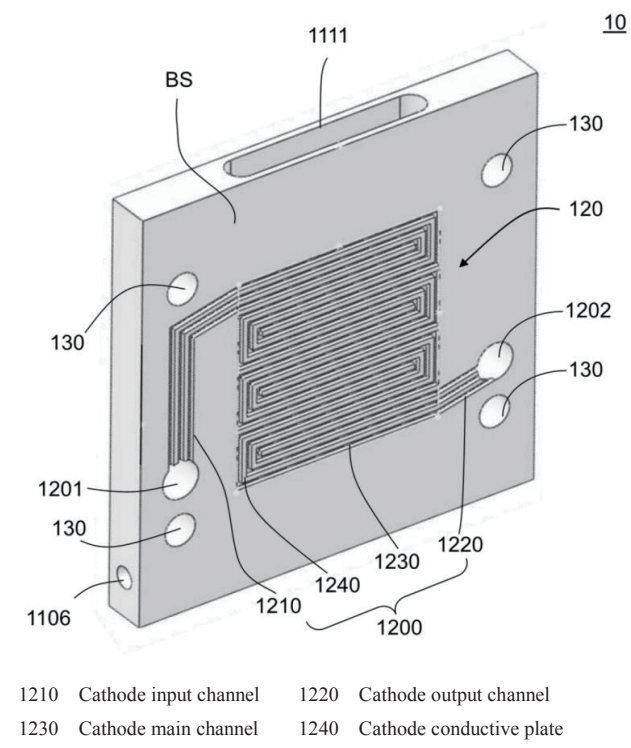

Fig. 3. 3D drawing of the cathode mechanism on the back side of the bipolar plate of a bi-electrolyte fuel cell mechanism.

This mechanism can be used to form a single cell by combining the anode mechanism of a monopolar anode plate, the cathode mechanism of a monopolar cathode plate, and MEA. Several bipolar plates and MEAs can be inserted between the monopolar anode plate and the monopolar cathode plate to form a cell stack. Through linkage of multiple cell stacks connected in parallel or series, the cell stacks can be used in electric vehicles.

The result is a range-extending charging-driving device for electric vehicles, as shown in Figs. 4 and 5. The wheel motor circuit connects with the main cell, and the wheel motor connects with the planetary gear assembly. Then, the planetary gear assembly connects with the wheel set. In addition, the range-extending charging-driving device also comprises an air compressor, which connects with the inside of the wheel motor.

\subsection{Methods}

This bi-electrolyte fuel cell can be refilled and reused. First, zinc powder is added to deionized water to make a paste. While stirring the zinc paste, $\mathrm{KOH}$ electrolyte is poured slowly into the paste to minimize the aggregated clusters of zinc powder. After that, the paste is ground and screened. The paste is loaded into the anode channel over a reactive area of $25 \mathrm{~cm}^{2}$. The fuel can be filled through the fuel inlet. The reaction products may be discharged through the surplus material discharge port at the lower part. Through the circulating electrolyte inlet, electrolyte is guided in to wash the anode channel. After the electrolyte is discharged through the surplus material discharge port, the fuel can be refilled again. The cathode input channel can be realized with an upward and extra-long shape. This structure increases the distance traveled by fuel from the fuel input communicating hole to the cathode main channel and decreases the inlet pressure at the cathode main channel into which air or oxygen flows. This design of a pressure damp can prevent the fuel input hole from directly supplying fuel to the cathode main channel, as it creates 


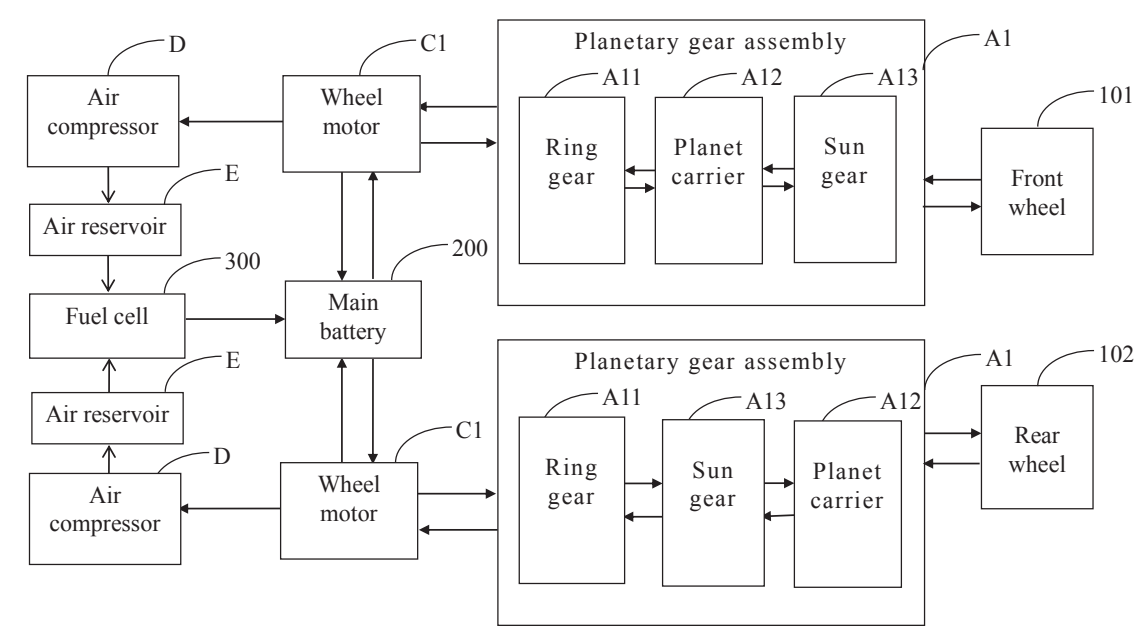

Fig. 4. Block diagram of the realization of the range-extending charging-driving device for electric vehicles.

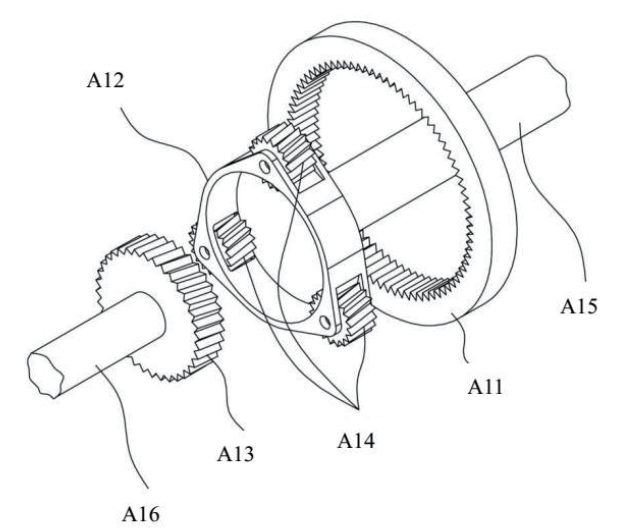

$$
\begin{array}{llll}
\text { A11 } & \text { Ring gear } & \text { A12 } & \text { Planetary carrier } \\
\text { A13 } & \text { Sun gear } & \text { A14 } & \text { Planetary gear } \\
\text { A15 } & \text { Planetary carrier shaft } & \text { A16 } & \text { Sun gear shaft }
\end{array}
$$

Fig. 5. Planetary gear assembly schematic diagram of one realization of the range-extending charging-driving device for electric vehicles.

the possibility of air/oxygen leakage. The anode output channel enables the fuel to flow from the bottom to the top. This is advantageous for the smooth discharge of gas after the reaction, and causes no gas leakage due to accumulated gas. The cathode main channel has multiple bends, and current is thus increased. For example, air/oxygen has a longer flowing time in the cathode mechanism, thus further increasing the chance and time to react electrochemically with the metal fuel in the anode mechanism of another cell template. Regarding the effect of the bottom-to-top channel to the fuel cell that produces water, the design makes use of gravity to let the water flow downwards smoothly and be discharged.

Figure 1 shows that a no-bend, vertical-array anode-conductive plate functions as the anode channel fuel guiding mechanism. It makes use of gravity to let metal fuel naturally flow downwards 
from the fuel inlet to the anode channel in the bi-electrolyte fuel cell. This design solves the final problem of channel blockage and resultant cell death, which are caused by aggregation and precipitation occurring after the anode metal powder of the bi-electrolyte fuel cell in the anode mechanism is mixed with the electrolyte. The anode conductive plate is combined with the anode channel, and encircles the anode conductive sheet to form a conductive body possessing multiple conductive sides to increase the probability of collision between the fuel elements in the fuel receiving chamber, allowing the reactive electrons to be easily guided out, and to decrease the probability of blockage. Therefore, the bi-electrolyte fuel cell can insure that reactants and products do not block the electricity collecting net. It is advantageous for the discharge of products and creates no blockage at the anode. By detecting and adjusting the flow, flow of electrolyte in and out is controlled, keeping the concentration and temperature of the electrolyte in the cell stable and improving the performance of the cell. This design not only solves the water management problems like flooding and dryness and avoids poor performance of the cell due to dehydration of the reactive film, but it also solves the temperature problem in the cell stack caused by connecting multiple fuel cells in series.

$n$ pieces $(n \geq 1)$ of bipolar plate, together with anode and cathode plates, can be used to assemble $n+1$ pieces of cell units. For a cell stack assembled using bipolar plates, if the number of single cells is $n$, then the number of electrode plates is $n+1$. If the cell stack is assembled using monopolar plates instead of bipolar plates, and if the number of single cells is $n$, then the number of electrode plates is $2 n$. Here, the advantages in quantity and weight are clearly shown. In this way, the weight, volume, and complicatedness of the fuel cell structure can be diminished.

Zinc powder $(3-9 \mu \mathrm{m})$ is blended in the $\mathrm{KOH}$ electrolyte with a concentration of $40 \mathrm{wt} \%$ to form a paste. The open circuit voltage is set to $1.4 \mathrm{~V}$; the constant voltage test method is used to test the device; and the reactive area is $5 \times 5 \mathrm{~cm}^{2}$. The fuel of cathode is increased to relative humidity of $100 \%$, and the temperature is increased to $60{ }^{\circ} \mathrm{C}$. We use AME1, AME2, and AME3 to make anion exchange membranes. It is found that AME2 at constant voltage $0.3 \mathrm{~V}$, current density $70 \mathrm{~mA} / \mathrm{cm}^{2}$, and power $P=0.53 \mathrm{~W}$ has the best performance. The testing stand is the model $850 \mathrm{e}$ compact fuel cell test system, shown in Fig. 6 .

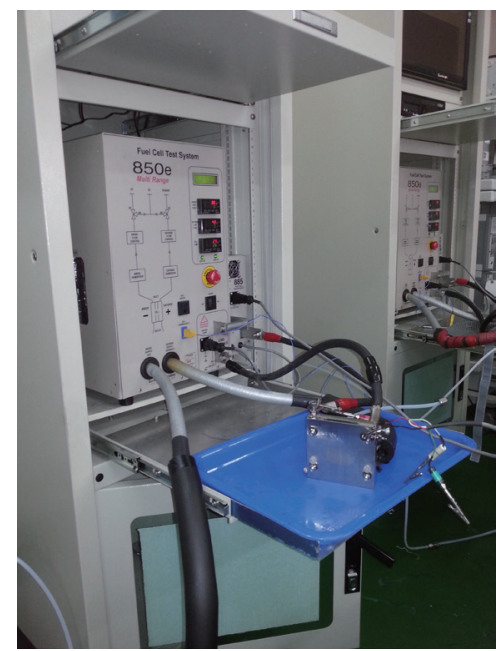

Fig. 6. (Color online) Fuel cell test system used in this work. 


\subsection{Methods of four-wheel direct-driven dual extended range system}

Regarding the range-extending charging-driving device for electric vehicles, when the wheel motor connects with and drives the planetary gear assembly, the wheel motor functions on the planetary gear assembly. Then, the planetary gear assembly drives the wheel set to turn. When the wheel motor is connected but has not driven the planetary gear assembly yet, the idling wheel set drives the planetary gear assembly, which then drives the wheel motor to generate electricity and thus charge the main cell.

When the wheel motor connects with and drives the sun gear shaft, the sun gear connects with and drives the planetary carrier, and then the planetary carrier shaft connects with and drives the wheel set. The sun gear is an input, the planetary carrier is an output, and the ring gear is held, making the wheel set slow down greatly in the same direction to enhance the torsion. When the wheel motor connects with and drives the planetary carrier shaft, the planetary carrier connects with and drives the sun gear. As a result, the sun gear shaft connects with and drives the wheel set, and then the planetary carrier serves as an input, the sun gear serves as an output, and the ring gear is held, making the wheel set speed up greatly in the same direction to increase the vehicle speed. When the wheel set is idling and the wheel set connects with and drives the sun gear shaft, and then the sun gear connects with and drives the planetary carrier, and as a result, the planetary carrier shaft connects with and drives the wheel motor to generate electricity. Subsequently, the ring gear is held, and the sun gear serves as an input, and the planetary carrier serves as an output. The planetary gear assembly slows down greatly in the same direction to charge the main cell. When the wheel set is idling and the wheel set connects with and drives the planetary carrier shaft, then the planetary carrier connects with and drives the sun gear. Consequently, the sun gear shaft connects with and drives the wheel motor to generate electricity, and then the ring gear is held, the planetary carrier serves as an input, and the sun gear serves as an output. The planetary gear assembly speeds up greatly in the same direction to charge the main cell.

An outer shaft of the wheel motor is used to drive at least one planetary gear of the planetary gear assembly to function, or is used to be driven by the planetary gear to generate electricity. The inner shaft of the wheel motor connects with the crank shaft to drive the piston inside the cylinder of the air compressor. The air compressor connects with the wheel motor. When the wheel motor functions or generates electricity to charge the main cell, the wheel motor drives the air compressor to compress air and supply the compressed air as fuel (containing oxygen) to the fuel cell. The fuel cell connects with the main cell to charge the main cell and to increase the cruising range. Furthermore, the time of electricity use for electric vehicles can be lengthened, decreasing the number of times that electric vehicle users have to look for charging station. The air reservoir connects with the air compressor. When the air compressor is being used to compress air, the air reservoir stores the air compressed by the air compressor.

\section{Results and Discussion}

This study refers to the previous studies of zinc-air fuel cells, and their problems and solutions are listed below: (1) Adding zinc powder to $\mathrm{KOH}$ electrolyte to form zinc blocks causes aggregation. We grind the zinc blocks to make them smaller particles, after which aggregation does not occur. (2) Zinc blocks cause a precipitation problem. We use the new vertical-array anode flow path 
instead of a serpentine flow channel to avoid precipitation of zinc blocks and to prevent zinc blocks from jamming at the corners of the serpentine flow channels. (3) Zinc powder has a continuous feed problem. We slot the upper part of the anode flow path and make use of gravitational forces to let the fuel in the anode flow path go downstream smoothly, rather than spreading the zinc sol onto the current collector. The battery is then assembled, but such a battery can only be used once and will not be used outside of the laboratory. (4) Eliminating the remainder of the unreacted zinc blocks is also a problem. We eliminated them by slotting an anode flow path at the lower part. (5) As to the problem of cleaning the zinc oxide product, we make a fuel output slot at the bottom of the anode flow channel to discharge fuel from the opening for circulating electrolyte. (6) For the problem that zinc blocks jam in the grid of the current collector, we use a conductive plate channel and a conductive sheet for vertical-array anode flow, which not only can lead the current out, but also can prevent the zinc blocks from jamming the grid of the current collector or staying in the net of foamed nickel. (7) The anode has the problem of producing water, thus causing flooding, creating water management issues, and even diluting the electrolyte concentration. There is also the problem of rapid reaction that causes excessive consumption and drying of the electrolyte and the problem of rising temperature of the cell stack connected in series by cells. To solve these problems, we use adjustable electrolyte with $\mathrm{KOH}$ electrolyte at a concentration of $40 \mathrm{wt} \%$, and maintain the concentration, capacity, and temperature of the electrolyte at a certain level. As shown in Fig. 7, the originally declining $I-T$ curve turns to rise again after using $\mathrm{KOH}$ electrolyte at a concentration $40 \mathrm{wt} \%$. (8) As the cathode needs water to react, we use a cathode fuel with a relative humidity of $100 \%$. (9) For the problem of electrolyte leakage, we refer to a past study ${ }^{(3)}$ and use PTFE to prevent leakage of electrolyte. However, there is also the problem that insufficient air enters the cell. We put three serpentine flow channels in the cell's cathode reaction area of $5 \times$ $5 \mathrm{~cm}^{2}$ to let air enter directly to avoid fuel shortage at the cathode. (10) The nonwoven insulation film has a problem of cross-over at the anode, which reduces cell efficiency and causes a great risk of battery short circuit. We use a solid electrolyte to isolate the anode from the cathode and allow $\mathrm{OH}^{-}$anions to pass through it and go to the anode to react. Originally, we wanted to use asbestos but did not use it because of safety and environmental concerns. (11) Anion exchange membranes have a problem in that they must be kept moist. We use cathode oxygen at $100 \%$ relative humidity to keep the membrane moist at temperature below $60{ }^{\circ} \mathrm{C}$ to promote reaction. As shown in Fig. 8,

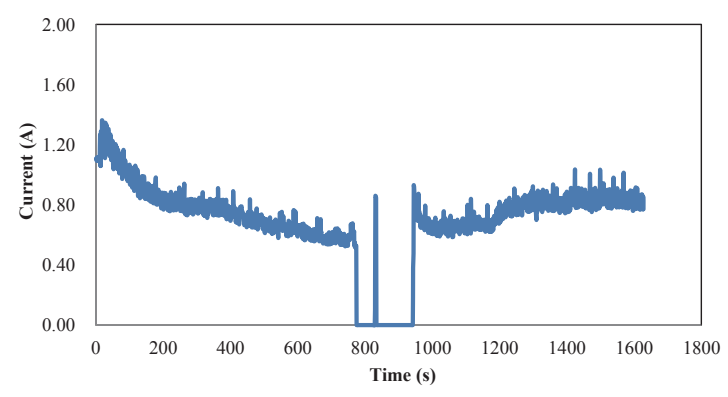

Fig. 7. (Color online) Current-time curve: Performance improved after increasing the $\mathrm{KOH}$ solution to a concentration of $40 \mathrm{wt} \%\left(T_{\text {cell }}=60^{\circ} \mathrm{C}\right.$, cathode fuel $R H=100 \%$ ).

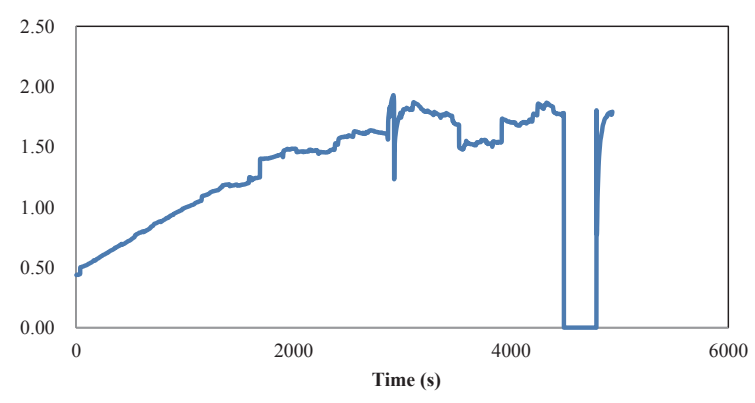

Fig. 8. (Color online) Performance improved after increasing the relative humidity of cathode and cell temperature. $\left(T_{\text {cell }}=60{ }^{\circ} \mathrm{C}\right.$, cathode $\left.R H=100 \%\right)$. 
after increasing the cathode's relative humidity, the curves rise continuously. (12) As found in the experiment, the anion exchange membrane moves in a direction as guided by ions, but upside-down charging causes performance degradation.

After using the commercially available 3-9 $\mu \mathrm{m}$ zinc powder for treatment, the $\mathrm{KOH}$ electrolyte at a concentration of $40 \mathrm{wt} \%$ is found to have better discharge and is aggregated into smaller particles. The open circuit voltage is set to $1.4 \mathrm{~V}$; the constant voltage test method is used to test the device; and the reaction area is maintained at $25 \mathrm{~cm}^{2}$. We use anion exchange membranes, AEM1, AEM2, and AEM3, and find that AEM2 is better than the other two under a constant voltage of $0.3 \mathrm{~V}$, a current density of $70 \mathrm{~mA} / \mathrm{cm}^{2}$, and a power of $0.53 \mathrm{~W}$, as shown in Fig. 9. AEM1, AEM2, and AEM3 are all obtained by commercial companies. This difference may arise because AEM1 is manufactured by the company itself, whereas the Fumatech supplied AEM3 that is obtained free of cost from another company, but both of them were untested, and hence, their quality cannot be guaranteed. Then, the authors purchased a new and unused membrane - AEM2, Aciplex A192 anion exchange membrane, made by Asahi Chemical, Japan, which was tested by Taiyen Biotech Co. Ltd. (Taiwan Salt), and hence, we were surer of its quality, as shown in Fig. 10.

In view of the realizations of this innovation for a range-extending charging-driving device for electric vehicles, through the configuration of wheel motor and planetary gear assembly installed at the wheels, the following is a description of its performance: (1) When the rear wheel motor connects with and drives the sun gear shaft, the sun gear serves as an input, the planetary carrier serves as an output, and the ring gear is held, making the rear wheel set slow down greatly in the same direction to enhance the torsion. (2) When the front wheel motor connects with and drives the planetary carrier shaft, the planetary carrier serves as an input, the sun gear serves as an output, and the ring gear is held, making the front wheel set speed up greatly in the same direction to increase the vehicle speed. (3) When the front wheel set is idling and the front wheel set connects with and drives the sun gear shaft, the ring gear is held, the sun gear serves as an input, and the planetary carrier serves as an output. The planetary gear assembly slows down greatly in the same direction to charge the main cell. (4) When the rear wheel set is idling and the rear wheel set connects with and drives the planetary carrier shaft, the ring gear is held, the planetary carrier serves as an input, and the sun gear serves as an output. The planetary gear assembly speeds up greatly in the same direction to charge the main cell.

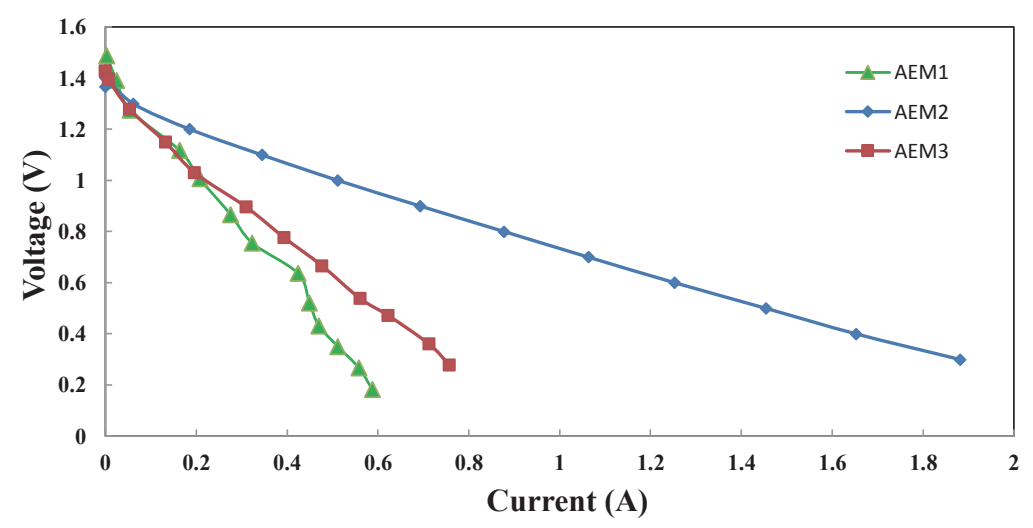

Fig. 9. (Color online) $I-V$ curves of AEM1, AEM2, and AEM3. 
(a)

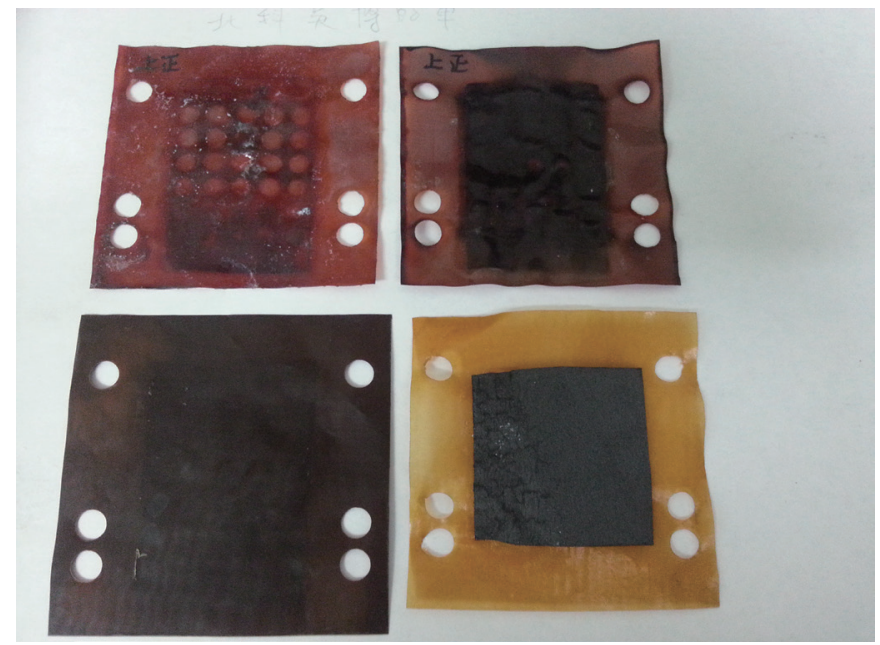

(b)

(d)

Fig. 10. (Color online) (a, b) AEM2, (c) AEM1, and (d) AEM3 after testing.

\section{Conclusions}

This study combines the refillable solid-liquid two-state electrolyte fuel cell with a new rangeextending charging-driving mechanism for electric vehicles, hoping that zinc-air fuel cells can move out of the laboratory and put into practical use, and thereby the practical use of electric vehicles can be promoted. This battery is the latest invention using anion exchange membranes. Although the results of the study do not illustrate their ideal performance, they have verified that this design of fuel cell is feasible. Because of DuPont's development of the Nafion cation exchange membrane, research and development of PEMFC has made great progress, indirectly proving that anion exchange membranes merit critical studies. In the future, we will carry out related studies in a strong alkaline environment, use quaternary ammonium groups $\left[-\mathrm{N}^{+}\left(\mathrm{CH}_{3}\right)_{3}\right]$ to study anion exchange membranes, and coat catalyst on cathode carbon cloth and hot-press anion exchange membranes to reduce their ohmic resistance.

\section{Acknowledgements}

This study is supported by The Fuel Cell Center of Yuan Ze University, Taiwan.

\section{References}

1 S. A. Bonev, E. Schwegler, T. Ogitsu, and G. Galli: Nature 431 (2004) 669.

2 C. Y. Wu: Taiwan Patent No. M500364 (2015).

3 C. Y. Wu, K. D. David, and H. Y. Tang: Adv. Mater. Sci. Eng. 2014 (2014). http://dx.doi.org/10.1155/2014/615391

4 H. Arai and M. Hayashi: Encyclopedia of Electrochemical Power Sources (Nippon Telegraph and Telephone Corporation, Atsugi, 2009) p. 55.

5 C. Chakkaravarthy, A. K. AbdulWaheed, and H. V. K. Udupa: Power Sources 6 (1981) 203.

6 G. Merle, M. Wessling, and K. Nijmeijer: J. Membr. Sci. 337 (2011) 1.

7 M. Mulder: Basic Principle of Membrane Technology (Kluwer Academic Publisher, London, 1991). 
8 K. S. Cole: Membranes, Ions, and Impulses, A Chapter of Classical Biophysics (University of California Press, California, 1968).

9 Y. Tanaka, S. H. Moon, V. V. Nikonenko, and T. Xu: Int. J. Chem. Eng. 2012 (2012). http://dx.doi.org/10.1155/2012/906952

10 J. R. Varcoe, J. P. Kizewski, D. M. Halepoto, S. D. Poynton, R. C. T. Slade, and F. Zhao: Fuel Cell - Alkaline Fuel Cell, Encyclopedia of Electrochemical Power Sources, Amsterdam: 329 (2009).

11 H. Deng, S. Huo, Y. F. Chang, Y. B. Zhou, and K. Jiao: Int. J. Hydrogen Energy 38 (2013) 6509.

12 S. Huo, H. Deng, Y. F. Chang, and K. Jiao: Int. J. Hydrogen Energy 37 (2012) 18389.

13 S. Yuan: Master Thesis of Department of Chemistry and Chemical Engineering, Shanghai Jiao-Tong University (2011).

14 J. J. Hwang: Fuel Cell (Chuan Hwa Publishing Ltd., Taiwan, 2005).

15 B. L. Yi: Fuel Cells: The Principles and Applications (Wu-Nan Book Inc., Taiwan, 2009).

16 K. B. Prater.: J. Power Sources 51 (1994) 129.

17 C. Y. Wu: Taiwan Patent No. M506736 (2015).

\section{About the Authors}

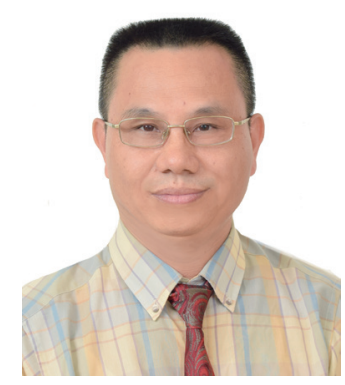

Mu-Jung Kao received his B.S. degree from the National Taiwan University of Technology, Taiwan, in 1986, his M.S. degree from Coventry University U.K., and his Ph.D. degree from the National Taipei University of Technology. He was an instructor at the National Taipei University of Technology, Taiwan, from 2002. He has been an associate professor at the National Taipei University of Technology, Taiwan, since 2008. His research interests are in nanfluid, nanomaterials, and thermoelectric generator.

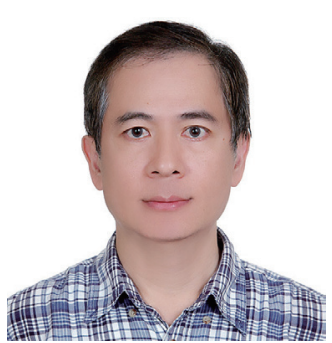

Chen-Yang Wu received his B.S. degree from the Chung Cheng Institute of Technology, Taiwan, in 1982 and his M.S. degree from the National Chung Cheng University, Taiwan, in 2003. From 1993 to 2002, he was a technical training engineer at Capital Motors Inc., Taiwan (Mercedes-Benz Distributor in Taiwan). His research interests are in fuel cells and electric vehicles. 